\title{
Expresión de bcl-2, ki-67 y caspasa-3 en lesiones cancerosas de la mucosa oral. Resultados preliminares
}

\author{
García García V*, González-Moles MA**, Bascones Martínez A***
}

\section{RESUMEN}

El cáncer oral representa del 2 al $4 \%$ de todos los cánceres diagnosticados, siendo el carcinoma epidermoide el tumor más común encontrado a nivel histológico. En varios estudios se ha constatado que el uso de la clasificación TNM del cáncer oral no resulta de utilidad a la hora de establecer el pronóstico tumoral. Nos encontramos en la era de los marcadores tumorales que actualmente pueden ser detectados y medidos con las más modernas técnicas de inmunohistoquímica. Material y método: aplicación de la técnica inmunohistoquímica peroxidasa- antiperoxidasa para la detección de las moléculas bcl-2, caspasa-3 y Ki-67 en lesiones cancerosas. Resultados preliminares y discusión: la detección molecular del marcador antiapoptótico bcl-2, el marcador proapoptótico caspasa 3 y el marcador de proliferación celular Ki-67 nos informará sobre la situación más o menos grave del paciente respecto de su proceso canceroso.

Palabras claves: Carcinoma epidermoide, Inmunohistoquímica.

\begin{abstract}
Oral cancer represents $2 \%-4 \%$ of all types of cancer that are diagnosed and epidermal carcinoma is the most common tumour found in oral cavity. Some experimental studies have shown that TNM classification is not useful when you want to know tumour prognosis. Now we are in the modern inmunohistochemical period with new techniques for cancer diagnose. Material and method: use the peroxidase-antiperoxidase inmunohistochemical technique to detect bcl-2, caspasa-3 and Ki-67 molecules in cancerous lesions. Preliminary results and discussion: molecular detection of the antiapoptotic bcl-2 molecule, the proapoptotic caspasa-3 molecule and the cellular proliferation indicator Ki-67 will show us about the gravity of the patient situation.
\end{abstract}

Key words: Epidermal carcinoma, Inmunohistochemistry.

Aceptado para publicación: Octubre 2005.

* Doctorado en el Departamento de Medicina y Cirugía Bucofacial. Facultad de Odontología. Universidad Complutense de Madrid.

** Profesor titular de Medicina Oral. Facultad de Odontología. Universidad de Granada.

*** Catedrático de Medicina y Cirugía Bucofacial, Departamento Estomatología III. Facultad de Odontología. Universidad Complutense de Madrid.

García García V, González-Moles MA, Bascones Martínez A. Expresión de bcl-2, ki-67 y caspasa-3 en lesiones cancerosas de la mucosa oral. Resultados preliminares. Av. Odontoestomatol 2006; 22 (5): 263-269. 


\section{INTRODUCCIÓN}

El cáncer oral representa del 2 al $4 \%$ de todos los cánceres diagnosticados, con un incremento anual de 5.000 casos nuevos por año (1), aunque cabe destacar la marcada variabilidad geográfica respecto a su incidencia.

Histológicamente, el carcinoma de células escamosas o epidermoide es el tumor más común encontrado en la cavidad oral constituyendo, aproximadamente, el $5 \%$ de todas las neoplasias (2) y el $30 \%$ de los cánceres de cabeza y cuello $(2,3)$.

Aunque la cavidad oral es un área accesible y examinada con frecuencia, es muy habitual el diagnóstico tardío del carcinoma epidermoide, asociándose por este motivo un porcentaje de supervivencia de tan sólo el $25 \%$ a los cinco años $(1,4)$.

En varios estudios se ha constatado que el uso de la clasificación TNM del cáncer oral no resulta de utilidad a la hora de establecer el pronóstico tumoral, pues hay tumores de gran tamaño que progresan benignamente, mientras que hay algunos tumores más pequeños que causan rápidamente la muerte del paciente (5).

Los avances científicos nos acercan a un punto donde el cáncer, en lugar de resultar una amenaza imprevisible, se va haciendo cada vez más previsible, más "conocido". Nos encontramos en la era de los marcadores tumorales que actualmente pueden ser detectados y medidos con las más modernas técnicas de inmunohistoquímica. En general estos marcadores participan y nos informan de mutaciones a nivel genético y de alteraciones en la proliferación y diferenciación celular alarmándonos precozmente sobre el comienzo de la malignización en un tejido.

\section{BCL-2, CASPASA-3, KI-67}

Los factores más decisivos para el desarrollo de un cáncer son las alteraciones en los mecanismos y porcentajes de la proliferación celular y de la apoptosis (6). El crecimiento tumoral podría definirse con la siguiente ecuación:
\% DE CÉluLAS ACuMULADAS = \% PROLIFERACIÓN CELULAR$\%$ muerte celular

Las modernas técnicas de inmunohistoquímica utilizan anticuerpos monoclonales y policlonales para poder detectar marcadores tisulares que nos informen tanto del \% de proliferación como de apoptosis existente en una determinada muestra de tejido perteneciente a una lesión cancerosa o precancerosa. Así, la detección molecular del marcador antiapoptótico bcl-2, el marcador proapoptótico caspasa-3 y el marcador de proliferación celular Ki-67 nos informará sobre la situación más o menos grave del paciente respecto de su proceso canceroso.

\section{Bcl-2}

El gen bcl-2 codifica una familia de proteínas de 25 $\mathrm{Kd}$, que se localizan en la membrana externa mitocondrial, en la envoltura nuclear y en el retículo endoplásmico de las células $(7,8)$. Se ha visto una sobreexpresión de bcl-2 en neoplasias hematopoyéticas y en variados tumores sólidos incluyendo cánceres orales.

La proteína bcl-2 se encuentra en muchos linfocitos B y T normales y su expresión disminuye en los centros germinales estimulados para la proliferación. El gen bcl-2 fue identificado por primera vez como el gen implicado en los linfomas B de células foliculares, de los cuales el $85 \%$ tiene como característica común la translocación del gen bcl-2 a la posición $14 \mathrm{q} 32(9)$.

La familia de bcl-2 se divide en dos grupos de proteínas, proapoptóticas como bax, bad y bak y antiapoptóticas como bcl-2, bcl-xL, mcl-1 y A1, según su estructura química (10-12). Las proteínas proapoptóticas y antiapoptóticas forman heterodímeros en los que se produce la inhibición de la actividad del otro respectivamente. Esta dimerización se ve influenciada por la fosforilación de los residuos terminales de aminoácidos de los miembros proapoptóticos, bax, bak y bik. Así pues, la apoptosis está muy relacionada con la fosforilación de las proteínas de la familia bcl-2 (10). El protooncogén bcl-2 bloquea una vía común de apoptosis, impidiendo que el ADN dañado actúe como una señal de activación de muer- 
te celular programada o mediante el bloqueo de los propios productos de los genes implicados en la muerte celular programada. Por lo tanto su acción es prevenir la muerte prematura de las células mitóticas y prolongar la supervivencia celular para favorecer la aparición de más mutaciones (9). La proteína bcl-2 no transforma las células por sí misma, pero las hace susceptibles de ser transformadas por otros oncogenes como myc (13).

\section{Caspasa 3}

Las caspasas pertenecen a una familia de cisteinproteasas que dividen sus sustratos específicamente después del ácido aspártico. Se han identificado 14 caspasas en mamíferos implicadas en la apoptosis. Son sintetizadas como proenzimas (zimógenos) de 30-50 KD y requieren un proceso de proteólisis para ser activados (8) que comprende una cascada de precursores y coenzimas (similar a las serin-proteasas en la cascada de la coagulación) (14), en la que las caspasas constituyen los componentes centrales de la maquinaria proteolítica (15).

De todas las caspasas, la caspasa-3 ha sido caracterizada como la más directamente vinculada a la apoptosis. Se ha sugerido que la expresión de la caspasa-3 aumenta la vulnerabilidad a la apoptosis o activa por sí misma la cascada de la apoptosis o hace ambas cosas a la vez. La caspasa-3 ha sido identificada en un amplio número de neoplasias benignas y malignas tales como ameloblastoma, carcinoma de células escamosas, cáncer de pulmón, neuroblastoma y linfoma. Algunas células normales, entre las que no se encuentran las células de Schwann, también expresan la caspasa-3 (6).

\section{Ki-67}

Ki-67 es una proteína nuclear no histónica expresada en las células durante las fases activas del ciclo celular (G1,S,G2,M), y ausente en las células en estado de reposo (G0). Por lo tanto, Ki-67 puede ser empleada para medir la fracción de crecimiento en los tejidos normales y en las neoplasias malignas. Estudios previos han demostrado que los altos índices de Ki-67 observados en carcinomas orales de células escamo- sas estaban correlacionados con la gravedad de la enfermedad y con un pronóstico malo $(16,17)$.

La capa basal del epitelio oral es la zona donde en condiciones normales se ubica el compartimento celular en proliferación, mientras que la capa suprabasal incluye las zonas de maduración celular. La detección de Ki-67 en la capa suprabasal es un marcador objetivo de la presencia de displasia epitelial (18).

\section{HIPÓTESIS DEL TRABAJO}

La hipótesis que desarrollaremos en el futuro, es que "la pérdida de la capacidad de inducir apoptosis por parte de las células tumorales aparece muy precozmente en el camino de la malignidad, incluso antes de que exista un fenotipo histológico claramente maligno".

\section{OBJETIVO DE LA INVESTIGACIÓN}

El principal objetivo de esta fase inicial de la investigación consiste en la puesta a punto de la técnica inmunohistoquímica peroxidasa- antiperoxidasa para la detección de las moléculas bcl-2, caspasa-3 y Ki-67. Bcl-2 es un marcador antiapoptótico, caspasa-3 es un marcador proapoptótico y Ki-67 es un marcador del índice de proliferación celular. La combinación de los tres marcadores nos permitirá hacernos una idea más clara del la gravedad de un cáncer oral de células escamosas.

\section{MATERIAL Y MÉTODO}

Para llevar a cabo la puesta a punto de la técnica se tomaron biopsias en cinco pacientes con lesiones orales correspondientes a carcinoma oral de células escamosas.

Del bloque de biopsias de cada paciente se obtuvieron tres cortes. En cada uno de los tres cortes se aplicó la técnica peroxidasa-antiperoxidasa con anticuerpos monoclonales para la detección de bcl-2 en el primer corte, caspasa-3 en el segundo corte y Ki67 en el tercer y último corte. En la detección mediante métodos inmunohistoquímicos hay que tener 
en cuenta que las proteínas mutadas tienen una vida media más larga, de hasta 48 horas, en comparación con los 5 a 30 minutos de la proteína normal, lo cual favorece la acumulación de la proteína (Vera y Navarro 1997).

El anticuerpo tiene una elevada afinidad para el reconocimiento y la interacción con el determinante antigénico. El acoplamiento de mecanismos de amplificación de señal, ya sea la unión del anticuerpo a enzimas, a fluorocromos o a isótopos radiactivos, permite la detección y posterior visualización de la reacción antígeno-anticuerpo. Para detectar las señales emitidas por estos reactivos se usan sustratos cromógenos que precipitan una vez que ocurre la reacción enzimática, produciendo un producto coloreado e insoluble en el sitio donde se encuentra localizada la enzima. La peroxidasa es una de las enzimas más usada, ya que es muy sensible y se puede usar en gran cantidad de sustratos.

\section{Procesado de las muestras}

Una vez obtenidas las muestras con bisturí las introducimos en formol al 3,5\% con un número de registro y unas siglas que representan al paciente. A continuación realizamos los baños con el sistema de alcoholes crecientes en el cuál el agua del tejido se sustituye por alcohol. Después se lleva a cabo un baño en xileno y así el alcohol se sustituye por xileno, y finalmente un baño en parafina dará lugar a que el xileno quede sustituido por parafina, obteniéndose de ese modo los bloques de parafina.

\section{Obtención de los cortes}

Tras introducir los bloques de parafina en una nevera a $4^{\circ} \mathrm{C}$ obtenemos los cortes de 3-5 $\mu$ con un micrótomo. Colocamos los cortes en los portas y se incuban en estufa a $37^{\circ} \mathrm{C}$ durante $24 \mathrm{~h}$.

\section{Desparafinización de los cortes}

Introducimos las muestras en 3 baños de xileno y en la batería de alcoholes decrecientes hasta llegar al agua destilada.

\section{Recuperación de epítopo}

En esta fase se pretende desenmascarar los antígenos que han podido quedar ocultos por determinados mecanismos. En una jarra "Coplin" se pone "target retrieval solution" (ChemMate TM) a pH 9 y se cargan las muestras dentro de la jarra. Se introduce la jarra "Coplin" en una olla a presión y se pone a hervir. Marcamos en los portas la muestra rodeándola con un lápiz de aceite (PAP- Pen) y los introducimos en agua destilada durante 3 ' lavándolos después con PBS (solución tampón).

\section{Técnica Peroxidasa- Antiperoxidasa. Sistema de visualización Envision (DakoCytomation)}

Se aplica la solución para el bloqueo enzimático endógeno-dual durante 5-10' y lavamos con PBS. Después se pone el anticuerpo primario o control negativo durante 30', volviendo después a hacer lavados con PBS (Figura 1).

A continuación se aplica el anti-anticuerpo (Polímero EnVision + HRP (Peroxidasa) durante 30'. Nuevamente lavamos con PBS e introducimos la solución de cromógeno DAB+ (Diaminobenzidina al 1,5\%) durante 5-10' (Figura 2).

Posteriormente lavamos con agua destilada, se hace la contratinción con hematoxilina y volvemos a lavar en agua corriente durante 20'.

\section{Deshidratación}

Se hacen los baños de alcoholes crecientes de 1' cada uno: desde el alcohol de $50^{\circ}$ hasta el alcohol absoluto.

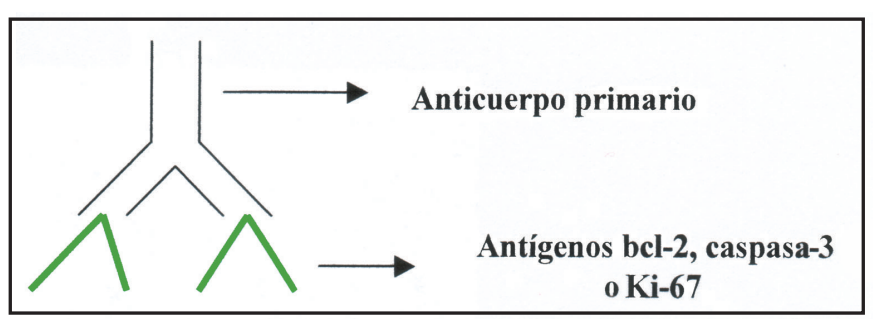

Fig. 1. Unión del anticuerpo primario con los antígenos. 


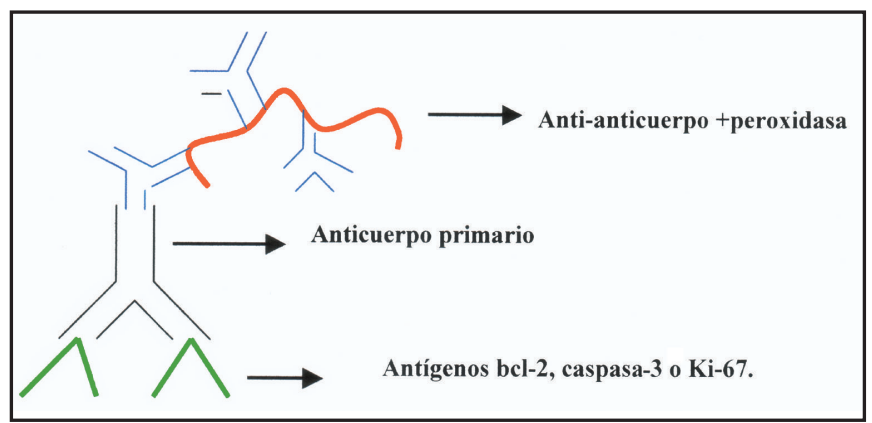

Fig. 2. Unión del anticuerpo primario con los antígenos a los antianticuerpos con la peroxidasa.

\section{Montaje}

Se realizan 2 baños de xileno de 2' cada uno y se colocan los cubreportas con pegamento eukitt.

\section{RESULTADOS PRELIMINARES Y DISCUSIÓN}

El crecimiento, la diferenciación y la proliferación celular son fenómenos finamente regulados por mecanismos moleculares que actúan a diferentes niveles del ciclo celular. Las células que sufren agresiones oncogénicas experimentan una serie de procesos destinados a parar el ciclo replicativo celular para reparar el ADN lesionado o inducir apoptosis (muerte celular) cuando el ADN tiene lesiones severas irreparables. Por estos mecanismos se previene que se establezcan clones de células con capacidad de reproducirse, que sean portadores de alteraciones en su genoma.

El mecanismo molecular que está prioritariamente implicado en el control del ciclo celular en células que han sufrido una agresión en su genoma es el sistema p53, constituido por el gen p53, localizado en el brazo corto del cromosoma 17, y su producto, la proteína p53. Habitualmente la proteína p53, que es la efectora de las funciones del sistema p53, se encuentra en forma normal o salvaje. En esta forma puede ejercer sus funciones fundamentales, que se concretan en la detención del ciclo celular para la reparación del ADN, o en el desarrollo de la apoptosis o muerte celular programada, para eliminar células con ADN portador de lesiones irreparables.
Cuando se produce un daño en el genoma, el gen p53 resulta frecuentemente lesionado. Habitualmente, la alteración del gen p53 es una mutación localizada en zonas diferentes del gen. Estas mutaciones permiten que se produzca proteína p53 mutada, que pierde su capacidad para regular el ciclo celular e inducir apoptosis. Así, las células que tienen una mutación del gen p53 pueden proliferar sin reparar su ADN o sin morir por apoptosis, de forma incontrolada, hasta establecer, generalmente con la colaboración de otros insultos oncogénicos, clones celulares malignos con capacidad de invasión.

La apoptosis puede ponerse de manifiesto mediante diferentes técnicas, aunque una de ellas considerada muy sensible y específica es la detección de la expresión de la proteína caspasa-3. Esta proteína pertenece a una familia proteica que se activa en cascada y que se expresa durante la apoptosis. Por tanto, al analizar la expresión de esta proteína en un tejido tumoral podemos deducir si en las células de una neoplasia concreta se están llevando a cabo mecanismos apoptóticos protectores. Muchos tumores tienen una expresión reducida de proteína caspasa-3, evidenciándose que el fracaso de este mecanismo apoptótico puede contribuir al crecimiento y a la proliferación de células epiteliales malignas. En la imagen se demuestra una expresión negativa de caspasa-3 tanto en el epitelio no tumoral adyacente al tumor (Figura 3) como en el propio tumor (Figura 4).

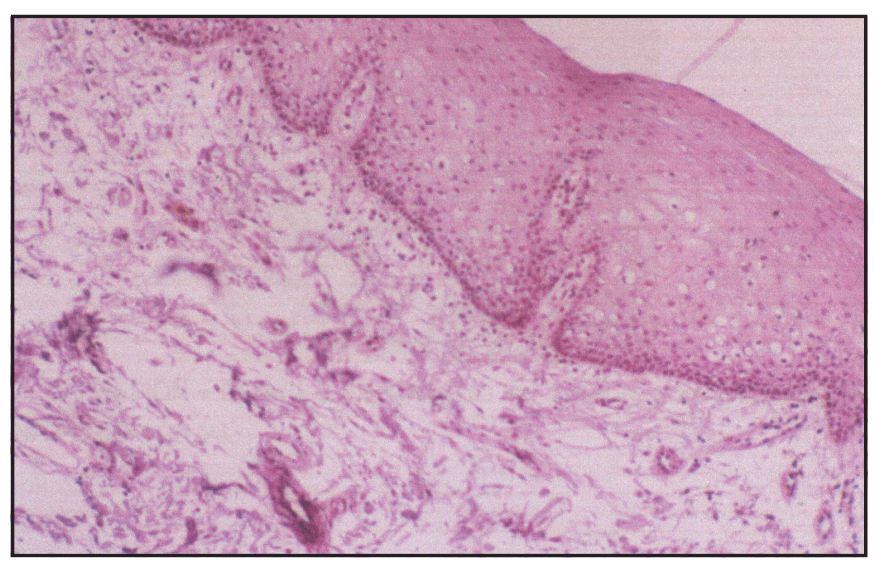

Fig. 3. Imagen negativa de caspasa-3 en epitelio no tumoral adyacente al tumor. 


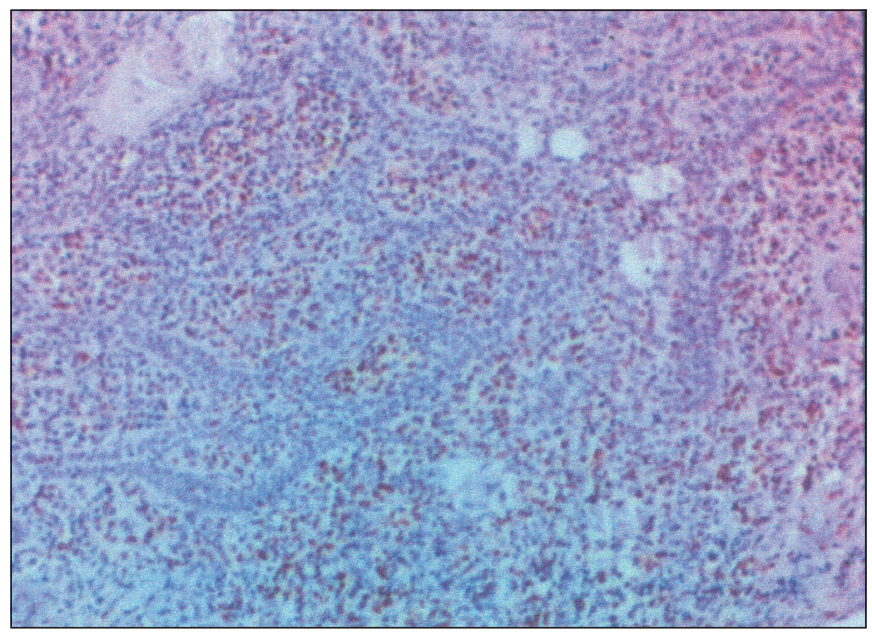

Fig. 4. Imagen negativa de caspasa-3 en el tumor y positiva en el infiltrado inflamatorio.

El epitelio no tumoral adyacente al tumor se considera un modelo muy apropiado para estudiar las alteraciones moleculares que acontecen precozmente en el desarrollo del cáncer, ya que se acepta que el tumor ha derivado de este epitelio y que por tanto las alteraciones moleculares oncogénicas que aparezcan en él son las más precoces en el desarrollo del tumor. Nuestra hipótesis que desarrollaremos en el futuro, es que la pérdida de la capacidad de inducir apoptosis por parte de las células tumorales aparece muy precozmente en el camino de la malignidad, incluso antes de que aparezca un fenotipo histológico claramente maligno. Como puede observarse en la figura 4 , aunque el epitelio tumoral es negativo para caspasa 3, sin embargo aparece una intensa expresión de esta proteína en el infiltrado inflamatorio adyacente a la neoplasia.

Se ha establecido que la incapacidad para el desarrollo de los fenómenos apoptóticos se lleva a cabo a través de las acciones del gen bcl-2 y de la proteína bcl-2 codificada por dicho gen. La función fundamental de la proteína bcl-2 consiste en inhibir la apoptosis permitiendo que células con ADN lesionado no mueran por apoptosis. Como puede observarse en la figura 5, aparece una expresión importante de bcl2 tanto en el epitelio no tumoral adyacente al tumor, como en el infiltrado periepitelial. Esto parece indicar que los fenómenos antiapoptóticos aparecen también muy precozmente en las lesiones precancerosas que posteriormente evolucionarán al desarrollo de un tumor (Figura 5).

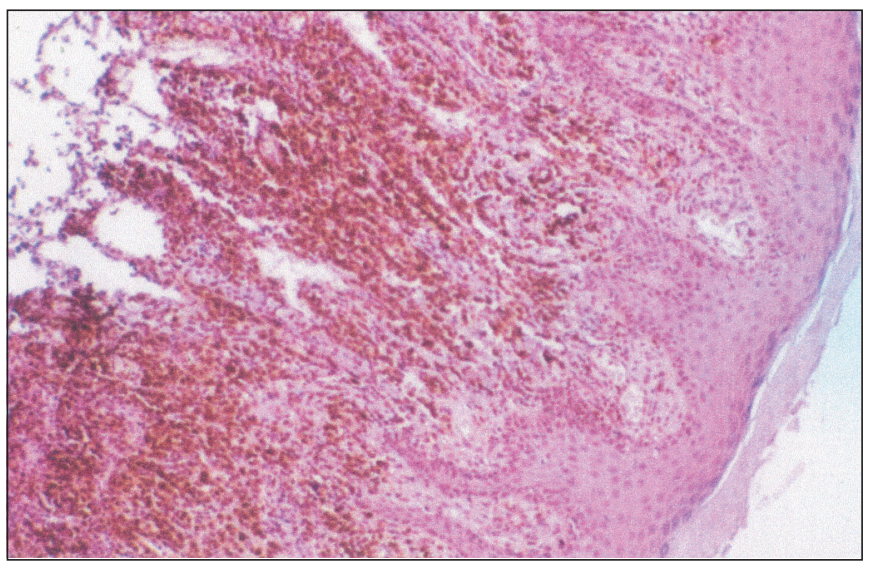

Fig. 5. Expresión + de bcl-2 en epitelio no tumoral adyacente al tumor y en zona periepitelial.

Finalmente, la ausencia de apoptosis y la inducción de mecanismos antiapoptóticos permiten que las células tumorales proliferen incontroladamente. El pronóstico de los tumores con frecuencia se relaciona con su capacidad de proliferación. Una forma precisa de medir el índice de proliferación celular de un tumor es la detección inmunohistoquímica de la expresión del antígeno Ki-67. Éste es una proteína que se expresa en la célula en cualquier fase del ciclo celular y desaparece durante el reposo celular o quiescencia. La expresión de Ki-67 probablemente se establece de forma inversa a la expresión de caspasa-3 y de forma directa a la expresión de bcl-2. En la figura 6 puede observarse una expresión positiva de Ki-67 en las células infil-

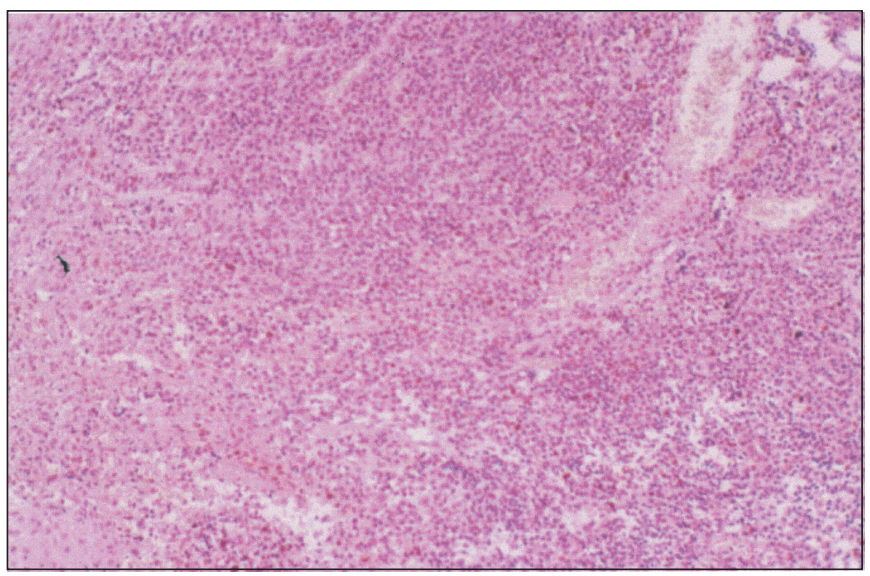

Fig. 6. Expresión + de ki-67 en las células infiltrantes de un carcinoma escamoso de la cavidad bucal. 
trantes de un carcinoma escamoso de la cavidad oral.

\section{BIBLIOGRAFÍA}

1. Jané Salas E. y cols. Importancia de la dieta en la prevención del cáncer oral. Med Oral 2003; 8:260-68.

2. Caribé Gomes F. y cols. Manejo odontológico de las complicaciones de la radioterapia y quimioterapia en el cáncer oral. Med Oral 2003;8:178-87.

3. De Vicente J.C. y cols. Expresión de las proteínas de los proto-oncogenes ErbB-3 y ErbB-4 en el carcinoma oral de células escamosas: estudio piloto. Med Oral 2003;8:374-81.

4. Gonzalez - Moles M.A. y cols. P21WAF1/CIP1 Protein and Tongue Cancer Prognosis. Anticancer Research 2004;24:3225-32.

5. Gonzàlez-Moles M.A. y cols. p16 Expression in Squamous Carcinomas of the Tongue. Onkologie 2002;25:433-6.

6. Chrysomali E. y cols. Immunohistochemical evaluation of cell proliferation antigen Ki-67 and apoptosis-related proteins Bcl-2 and caspase-3 in oral granular cell tumor. Oral Surg Oral Med Oral Pathol Oral Radiol Endod 2003; 96:566-72.

7. Tanuja T. y cols. Expresión of Bcl-2 and Bax In Chewing Tobacco-Induced Oral Cancers and Oral Lesions from India. Pathology Oncology Research 2002; 8 (2):109-14.

8. Loro L. y cols. Cell death regulation in oral squamous cell carcinoma: methodological considerations and clinical significance. J Oral Pathol Med 2003;32:125-38.

9. Mc Alinden RL. y cols. Bcl-2 expression in sequential biopsies of potentially malignant oral mucosal lesions assessed by immunocytochemistry. Oral Diseases 2000;6:318-26.
10. Dechao L. y cols. Reactive oxygen species (ROS) control the expression of Bcl-2 family proteins by regulating their phosphorylation and ubiquitination. Cancer Sci 2004;95:644-50.

11. Loro L. y cols. Decreased expression of bcl-2 in moderate and severe oral epithelia dysplasias. Oral Oncology 2002; 38:691-8.

12. Schoelch M. L. y cols. Apoptosis-associated proteins and the development of oral squamous cell carcinoma. Oral Oncology 1999;35:77-85.

13. Gibson S. y cols. Induction of Apoptosis in Oral Cancer Cells by an Anti-bcl-2 Ribozyme Delivered by an Adenovirus Vector. Clinical Cancer Research, Vol.6, 213-222, January 2000.

14. Tong D. y cols. 5-Fluorouracil-induced apoptosis in cultured oral cancer cells. Oral Oncology 2000;36: 236-41.

15. Kudo Y. y cols. p27Kip1 Accumulation by Inhibition of Proteasome Function Induces Apoptosis in Oral Squamous Cell Carcinoma Cells. Clinical Cancer Research Vol. 6, 916-923, March 2000.

16. LlamaronA. y cols. Co-expression of p53 and Ki67 and lack of EBV expresiónin oral squamous cell carcinoma.Oral Path Med,2004.33;30-6.

17. García - Pola Vallejo M.J. y cols. Estudio comparativo de la expresión del Ki-67 en el liquen plano oral y la leucoplasia oral. Análisis cuantitativo. Med Oral 2001; 6: 364-70.

18. González-Moles M.A., Rodríguez-Archilla A. Suprabasal expression of Ki-67 antigen as a marker for the presence and severity of oral epithelial dysplasia. Head and Neck 2000; 22: 658-61.

\section{CORRESPONDENCIA}

Virginia García García

virginiaborj@hotmail.com. 